\title{
Moral Gods and the Origins of Human Cooperation
}

\section{Ylikoski, Petri Kullervo}

Brill

2017

Ylikoski , P K 2017 , Moral Gods and the Origins of Human Cooperation . in P Luomanen , A

B Pessi \& I Pyysiäinen (eds), Christianity and the Roots of Morality : Philosophical, Early

Christians and Empirical Perspectives . , 2 , Philosophical Studies in Science and , vol. 8 , Brill , Leiden , pp. 25-44 . https://doi.org/10.1163/9789004343535_003

http://hdl.handle.net/10138/310075

https://doi.org/10.1163/9789004343535_003

unspecified

acceptedVersion

Downloaded from Helda, University of Helsinki institutional repository.

This is an electronic reprint of the original article.

This reprint may differ from the original in pagination and typographic detail.

Please cite the original version. 
Published 2017 in Christianity and the Roots of Morality (edited by P. Luomanen, A. Pessi, \& I. Pyysiäinen), Leiden: Brill: 25-43.

\title{
Moral Gods and the Origins of Human Cooperation
}

\author{
Petri Ylikoski \\ Sociology \\ University of Helsinki \\ petri.ylikoski@helsinki.fi
}

This article discusses the role of belief in gods in the development of human prosociality and cooperation. The emergence of large-scale human cooperation is a theoretical puzzle that has given rise to a number of quite different hypotheses. Several authors have suggested that religion could have played a crucial role in the expansion of human altruism beyond kinship. The article focuses on and questions the specific claim that belief in supernatural surveillance and punishment (SSP) played a crucial role in the evolution of human cooperation. I will argue that the idea of gods being interested in human morals is a quite late idea and that the most crucial developments in human social organization had already occurred when it arose. The religious ideas associated with the Axial religions have had a significant historical influence, but only during the last 2000 years.

More generally, I suggest that this case study on the status of the SSP hypothesis also provides a methodological lesson. We should not treat religion as a natural kind that has a belief in moral gods as its essential feature. Attributing modern ideas about gods to early thinking about supernatural agents is a major methodological failure. If we are truly interested in the evolution and history of human morality we should be much more sensitive to the historical development of religious ideas. In other words, we should avoid anachronistic inferences in the study of religion and morality.

\section{The problem of human cooperation and religion}

The topic of this paper is the role of religion in the evolution of the human capacity for moral behavior. This is a huge topic that includes two very complicated issues: religion and morality, neither of which I will discuss fully. 
As to religion, I will only discuss a specific group of ideas about gods. More precisely, I will focus on the idea that gods are motivated to evaluate human moral behavior and capable of acting on this judgment, in this world or in the afterlife. Thus I will say nothing about gods as objects of worship or about their role in cosmological theories. Moreover, religion includes much more than its ideas about gods: for example religious experiences, rituals, specific social practices, and so on. I will say nothing about these either. However, one of the main conclusions of the paper is that if one is interested in the role religion has played in the evolution of human morality, one should focus more on these other aspects of religion. Another important lesson would be that treating religion as a natural kind is a script for disaster in studies that track long-term historical developments. I will return to these lessons at the end of the paper.

As well, I address morality only partially. I will only discuss altruistic helping, prosociality, and large-scale cooperation, as these are concepts that are used in the literature that I am addressing (Dubreuil 2010). These behavioral concepts are not the same as morality: they do not necessarily involve moral emotions (such as guilt, shame, indignation, or anger), moral conscience, or moral reasoning that appeals to moral standards. However, they provide a context in which the latter have evolved. The unique human capacity and motivation for moral cognition evolved for the purposes of social life, and it is plausible to assume that the key changes in prosociality and cooperation would be indicators of changes in our ancestors' moral cognition. The organization of human social life provided a matrix for the evolution of morality, and for this reason can be used as a proxy for its development.

The specific idea I will be addressing is the supernatural surveillance and punishment hypothesis (SSP), which claims that the idea of supernatural surveillance and punishment played crucial role in the emergence of human cooperation. The key idea is that once people began believing in supernatural agents that are interested in how humans behave, the fear of punishment by these everpresent observers made them behave in a more prosocial manner. Thus they would abstain from breaking social norms even in situations where other group members would not have been able to observe them. We can distinguish two versions of this hypothesis in the recent literature. According 
to what I call the "early" version, the emergence of the idea of SSP explains the emergence of cooperation during the Pleistocene (Johnson \& Krüger 2004; Johnson 2005; Bering \& Johnson 2005, 2006). In contrast, the "late" hypothesis states that SSP contributed crucially to the emergence of large-scale cooperation during the Holocene (Shariff \& Norenzayan 2008; Shariff, Norenzayan \& Henrich 2010; see also Kitcher 2011). The differences between these hypotheses do not merely concern the timing of the influence, but also concern the evolutionary mechanisms by which SSP had its influence.

Here is the idea of the early version in the words of its main advocates:

If the chance and costs of exposure are high enough, individuals who were more likely to refrain from cheating for fear of supernatural agents concerned with group norms (indeed, such agents are often the proposed authors of these norms) and who punish defectors by inflicting misfortune (on both the self and innocent others) could have out-reproduced otherwise equal - and more indiscriminately selfish - individuals. (Johnson \& Bering 2006: 227-228)

These authors propose that what prompted our ancestors to adopt non-selfish and group-oriented behaviors was a belief in supernatural punishment. The key idea is that believing in SSP induced people to make a self-interested calculation - they attempted to avoid supernatural punishment either in this life or in the afterlife - that led them to adopt more prosocial behaviors. As a result of these decisions, those ancestors who were able to entertain such beliefs about supernatural punishers were able to acquire a clear advantage in terms of biological fitness. The hypothesis is not very specific about the timing, but we can roughly identify the evolutionary period. First, the hypothesis presupposes an ability to operate with mental concepts (Johnson \& Bering 2006). Thus believing in supernatural surveillance and punishment is only possible after the development of the theory of mind. Second, as human cooperation did not begun as large scale cooperation, the proposed mechanism had to have started working before the development of large-scale societies some 10000 years ago. This timing is not very precise, but it helps us to distinguish the early 
hypothesis from the late one, as the latter is exclusively focused on the development of later largescale cooperation.

Another distinguishing feature of the early hypothesis is the proposed evolutionary mechanism. Supporters of the early hypothesis talk about the individual-level genetic advantages of belief in SSP, thus suggesting that we have biologically adapted to it. The nature of the underlying adaptation is not made clear, but presumably it involves changes in cognition that make the adoption SSP-like beliefs easier and facilitate SSP-related thinking. The idea of biological adaptation of course implies that the evolutionary build-up of these cognitive features should have began a long time ago.

In contrast, the late hypothesis claims that the effects of SSP on human cooperation are from an evolutionary perspective quite recent. According to this version of the hypothesis, belief in SSP is a cultural adaptation. Here the key idea presented by prominent supporters of the late hypothesis is presented as follows:

... omniscient, moralizing supernatural agents derived from a suite of religious beliefs that were culturally selected for their ability to galvanize cooperation in larger groups, promote ingroup cohesion, and foster competition with other social groups. (Shariff, Norenzayan \& Henrich 2010: 119)

Supporters of the late version propose cultural group selection as the key evolutionary mechanism. The central idea is that groups with SSP-like ideas have been favored by cultural evolution. These groups were more successful in tasks that required large-scale cooperation - such as building irrigation systems, conducting warfare and developing extensive trade networks - making their survival and growth more probable (Shariff, Norenzayan \& Henrich 2010). This hypothesis does not presuppose a process of genetic adaptation; rather it based on the social transmission of ideas. The notion is simply that groups whose members believed in supernatural surveillance were more prone to act prosocially in new situations where the mechanisms that supported cooperation in smaller hunter-gatherer societies - such as surveillance by others, reputation and the threat of social isolation - could not function. So here the key idea is not the initiating of cooperation, but the expansion of cooperation to a scale that makes larger societies possible. 
Note that the early and late hypotheses are analytically distinct; they are not formally incompatible, and it is possible to subscribe to both. For example, Dominic Johnson might support both (Johnson 2005). However, I want to clearly distinguish the two hypotheses as conceptually distinct hypotheses whose fate will determined by quite different pieces of evidence.

In what follows, I will focus mostly on the early hypothesis. This is because it links the idea of SSP with the emergence of human morality, while the late hypothesis already presupposes humans having some kind of morality. I will also ignore some of the salient theoretical problems concerning the formulations of the early hypothesis. For example, Bering and Johnson seem to confuse evolutionary, behavioral, and psychological selfishness in a manner that ultimately makes their model incoherent ${ }^{1}$. Secondly, they quite optimistically assume that a rather simple prisoner's dilemma model captures the most crucial social dilemma of our hunter-gatherer ancestors. This optimism has been challenged by more recent theorizing in evolutionary game theory (Baumard $201 \mathrm{oa}, \mathrm{b})$. Finally, they are very silent about the evolutionary and genetic mechanisms underlying our presumed adaptation to SSP-like beliefs (see also Schloss \& Murray 2011, and responses to it). I will only focus on the evidence that could support the hypothesis and how implicit essentialist assumptions about religion lead to mistaken claims about evidential support.

\section{The experimental evidence}

SSP supporters have appealed to certain experimental evidence. I will here deal only with the two most prominent examples and use them to make some observations about the relevance of the contemporary experimental data.

The first experiments to be considered are the priming experiments of Azim Shariff and Ara Norenzayan. In them, the subjects were first primed with God-related or neutral concepts in order to implicitly activate their God-related thoughts, after which they were asked to participate in an

\footnotetext{
1 Consider, for example, the following passage: "Because human behaviors are unconsciously motivated by genetic interests, individuals should have evolved to be motivated to refrain from any behaviors that are believed to threaten inclusive fitness" Bering \& Johnson 2005: 127). So we have both unconscious motives and explicit beliefs about threats to inclusive fitness. It not clear at all how all these mesh together and whether the result will be compatible with what is known about human evolution and cognition.
} 
economic game (the Dictator game) that measured their willingness to give to anonymous coplayers. The results showed that people primed with ideas associated with God gave significantly more to anonymous strangers. Therefore thoughts about God, activated without conscious awareness, seemed to prompt greater generosity. According to Shariff and Norenzayan, these results support the idea that the imagined presence of a morally concerned supernatural watcher reduces the anonymity of the situation and heightens prosocial reputational concerns, thereby increasing prosocial behavior (2008: 60).

However, it is not at all clear that this inference is justified. First, the increased giving when primed with religious concepts also occurred when the subjects were atheists. Furthermore, similar effects were achieved when subjects were primed with secular morality-related concepts. These results require explanation as well. A plausible reason is that thoughts of God and thoughts of benevolence are cognitively associated, just as the ideas of law and morality are. When the ideas about God, or any other concepts associated with morality, are primed, they increase behavioral tendencies that are consistent with prosocial behavior (Galen 2012). This mechanism is needed in order to explain the effects of secular primes, so it is also available for God-related primes. Thus SSP is completely unnecessary for the explanation of these experimental outcomes. The only thing these experiments show is that contemporary Americans implicitly associate God with moral behavior. This association of concepts does not require that one be religious. All that is required is the familiarity with the relevant cultural codes. Naturally, this cultural fact does nothing to show that people thousands or even tens of thousands of years ago had the same conceptual associations.

Experiments that have observed that the mere presence of picture of human eyes in a room increases human prosocial behavior are a second source of evidence (Bateson, Nettle \& Roberts 2006; Ernest-Jones, Nettle \& Bateson 2011). While the results of these experiments have been variable (Ekström 2011), they show that cues such as eyes (in some experiments three dots in the form of letter "v" are sufficient) can induce prosocial behavior, for example, cleaning up garbage or paying for borrowed milk. Explaining these results is not difficult. External cues such as eyes apparently trigger subconsciously implicit associations that make behavior felt to be proper in the 
eyes of others more probable. Given that people are sensitive to the presence of others and are concerned about their reputations, it is plausible that observational scripts related to observing others get automated and thus can get triggered subconsciously.

It is difficult to explain how these observations could support the SSP hypothesis. First, the subjects in the experiments seem to have made implicit inferences about the presence of other people, not of gods. Nor did they report having thoughts about supernatural agents. So the SSP hypothesis seems to have only a tenuous relation to these experiments. Furthermore, the hypothesis is not about external observational cues, but about beliefs about supernatural agents and their motivation. Unless the theory implausibly assumes that people entertain explicit beliefs about morally concerned gods, it needs a mechanism by which these beliefs are activated in morally relevant situations. This ability to recognize situations that are morally relevant sounds very much like conscience. If SSP is presented as an explanation of the origins of human morality, as it does in the early hypothesis, presupposition like this sounds illegitimate, or at least question-begging.

This critical point can be extended to other experiments. For example, if university students who have been casually told that the ghost of a dead student had been spotted in the experiment room cheat less in computer tasks (Bering 2006), we should treat this suggestion as a cue analogical to the eyes on the wall. Similarly, if children obey instructions better when they are told that a fictional supernatural agent - Princess Alice - is watching them, we are dealing with a similar cue about the presence of others. Although the agents in these experiments are supernatural, they can still be interpreted as cues to implicit processes that are related to observing other persons. Furthermore, such agents are in any case far removed from the moral gods presupposeed by the SSP hypothesis. They would at most observe how persons might behave, but they are not assumed to be either able or motivated to punish for violations. Therefore these experiments do not support the SSP hypothesis, although they are compatible with it.

A similar failing can be recognized in appeals to contemporary non-experimental evidence. Often cited by those who support the SSP hypothesis is study by Sosis and Alcorta (2003), who compared the longevity of secular and religious communes in 19th Century North America and observed that 
life expectancy of religious communes was longer. Sosis and Alcorta use this evidence to support their own costly signaling theory of religion. Their paper does not discuss the role of believing in supernatural surveillance and punishment, which is understandable as, the costly signaling theory is mostly about rituals. It is surprising, that supporters of the SSP hypothesis are so eager to cite this study in support of their own hypothesis. Formally, the evidence provided by Sosis and Alcorta is compatible with the SSP hypothesis, but fails to support it. Many aspects of religious community life could explain the longevity observed in these communes, so it is a mistake to automatically assume that a belief in SSP is the cause, even if it is beyond doubt that these Christian sects did in fact believe in SSP.

These appeals to apparently irrelevant evidence call for an explanation. I would propose that the key mistake made by SSP supporters is essentialist thinking about religion. Because they assume that a belief in supernatural agents who are motivated and able to observe and punish comprises the core of any religion, they automatically assume that this core feature is also responsible for the important consequences of religion. This is a fallacy. Religion contains many elements - including religious experience, beliefs and doctrines (e.g. concerning cosmology, history, and morals), sacred texts, rituals, communities and organizations - that are not systematically associated with each other. For example, only some religions are based on the idea of moral gods. It is also a mistake to assume that all consequences of religion - such as its prosocial or less positive effects - are due to its particularly religious elements (Galen 2012). Simply put, there is no core essence of religion that is responsible for all of its most significant causal effects. These effects must be studied on a caseby-case basis, and one should avoid anachronistic inferences from present religions to past ones. Thus the assumptions about the religious life among ancestral hunter-gatherers or inhabitants of early state-like societies are something that cannot be made as a matter of course, but must be supported by evidence.

\section{The long history of religions}

Both SSP hypotheses are basically historical claims about the past. The early hypothesis states that hunter-gatherers who predate large-scale societies believed in SSP and that it played crucial role in 
the evolution and development of human cooperation. In contrast, the late hypothesis states that SSP played a crucial role in the emergence of large-scale human cooperation during and after the invention of agriculture some 10000 years ago. The formulation of the late hypothesis is vague, but I assume that the claim concerns the time before the Axial Age, as otherwise the hypothesis would have a little novelty value. The key question with respect to both hypotheses is the question of when people began to believe in gods who were 1) particularly interested in the moral behavior of humans toward other humans, 2) powerful enough to control events in the world and especially in the afterlife, 3) knowledgeable about people's behavior (and maybe even about their inner thoughts), and 4) possibly impartial, or even benevolent, with respect to the members of the religious group. The key idea here is that gods are assumed to be interested in how well people obey the norms that govern relations between humans, rather than being merely focused on obedience to the rules that concern relations between the $\operatorname{god}(\mathrm{s})$ and humans. Another important idea is that of an afterlife. The idea of reward and punishment in this life is probably quite difficult to sustain for long periods of time, so we have to also consider when people began to believe in a morally contingent afterlife, i.e. an afterlife that depends on judgments of their moral behavior during their lives.

Let us start with what is known about ancestral hunter-gatherers. All humans lived as nomadic hunter-gatherers until the invention of agriculture (and pastoralism developed in parallel with agriculture). Based on observations about later hunter-gatherers, some things can confidently be said about their social organization (Marlowe 2005). These people lived in small groups that consisted of both relatives and non-relatives; furthermore, the kinship relations created networks of relations between these groups (Hill, Walker, Božičević, Eder, Headland, Hewlett \& Hurtado 2011; Apicella, Marlowe, Fowler \& Christakis 2012). Hunter-gatherer societies are often characterized as being egalitarian (Woodburn 1982, Boehm 1999). This does not mean that they exemplified modern ideas about equality, but rather that these groups lacked permanent hierarchies that would endure over generations. Bullying and other attempts at domination could be handled by collective action 
(the invention of hunting weapons were great levelers in this respect) or by simply leaving the group (Boehm 1999).

Ancestral hunter-gatherers probably had various rituals and customs that we would characterize as religious. (Naturally they would not have had our notion of religion, as they had nothing to contrast it with.) But what about their beliefs with respect to gods? They definitely had mind-reading ability and language, that are preconditions for belief in gods and other supernatural agents. Given what we know about human cognition, we can be quite confident that these people had minds that were active in the detection of agency and biased towards giving intentional explanations for things. Thus they definitely postulated various agents that we would call supernatural (Pyysiäinen 2009). Similarly, they had an ability for "mental time-travel" and metarepresentation, so there is little doubt they had beliefs concerning what might occur after death. This assumption is also supported by archaeological grave findings. None of this is in dispute. However, the key point is that these things are not sufficient grounds for the early SSP hypothesis. What was needed were powerful gods interested in the moral behaviors of humans, and beliefs about a morally contingent afterlife. As far as I can judge, there is very little evidence of these.

A look at comparative anthropological research is revealing. It takes as its starting point collections and atlases of ethnographic descriptions of different societies and conducts statistical analyses of the co-occurrence of attributes of interest. As the analysis of all known societies would be very time-consuming and pose serious methodological problems, the researchers typically operate on samples of human societies. For instance, the Standard Cross-Cultural Sample, containing some 186 societies, has been popular in recent research as it is assumed to provide a representative sample of world cultures (Snarey 1996; Roes \& Raymond 2003; Johnson 2005; Sanderson \& Roberts 2008; Bourrat, Atkinson \& Dunbar 2011; Peoples \& Marlowe 2012). While these comparative studies have their methodological problems - such as many of the cultures having been influenced by missionaries (Snarey 1996), the uneven skill level of the ethnographers, and various biases introduced by the informants used (Barnes 2000) - they provide a valuable perspective on human religion. 
Peoples and Marlowe (2012) studied the relation between society's mode of subsistence and its beliefs in gods. Regarding the latter, they used Guy Swanson's famous High God variable. A High God is a spirit who is said to have created all reality and/or is reality's ultimate governor. The variable can have four different values. People might 1) have no ideas about High Gods, 2) believe that High Gods exist, but that they are not active in human affairs, 3) believe that High Gods are active in human affairs, or 4) believe that High Gods are morally interested in human affairs. This is a very interesting variable, as the SSP hypothesis presuppose that people believe in gods who are active and morally interested in human affairs. In fact, if we take seriously the suggestions about genetic adaptation, the early hypothesis predicts that believing in moral High Gods should be universal. (The late hypothesis is more tolerant of the variation.) Thus societies which lack moral High Gods count as evidence against the SSP hypothesis. If the High Gods are absent, or are believed to be inactive or uninterested in moral issues, they cannot serve as guarantors of social order.

Peoples and Marlowe's results are quite clear. Of the 33 forager societies they examined, only 4 had active or moral High Gods. This indicates that something is seriously wrong with the early hypothesis. If the hunter-gatherer societies that modern explorers and anthropologists have encountered mostly lack a belief in moral High Gods, it is not plausible to assume that ancestral hunter-gatherers who lived tens of thousands years ago had such beliefs. Other comparative studies (Snarey 1996; Roes \& Raymond 2003; Sanderson \& Roberts 2008; Bourrat, Atkinson \& Dunbar 2011) support this conclusion: ideas about High Gods become prevalent only when the size and complexity of the society increases.

What about the late hypothesis? The lack of moral High Gods among hunter-gatherers is compatible with it. Foragers who live in small and mobile egalitarian groups have little use for the social constraints of High Gods (who are much like "high rulers") as their societies do not produce few large-scale social action problems (Peoples \& Marlowe 2012). The late hypothesis also receives partial support, as things like the size of the society, the mode of subsistence, and the complexity of social relations correlate with believing in High Gods and other dimensions of the development of 
religion. For example, Peoples and Marlowe suggest that an important selective force promoting the concept of a morally concerned High God was the herding and keeping of animals. The herding of animals means a world full of moment-to-moment contingencies requiring cooperation, and the wealth that accumulates increases the probability of raiding and warfare. Similarly, settled agriculturalists who rely on a controlled production of resources within a circumscribed area face similar threats. The greater food production will also ultimately increase the group size, thus increasing the need for social coordination. In such a situation, the idea of a High God who sets codes of conduct and who backs them with the threat of supernatural punishment could be useful.

However, this comparative data provides no decisive support for the late SSP hypothesis, which is basically a historical hypothesis stating that the belief in SSP played an important or crucial role in the emergence of large-scale human cooperation. The problem with the comparative studies in this regard is two-fold. First, their data concern relatively recent societies, so they cannot inform us when the relevant religious ideas were developed and whether they had been transmitted from one society to another. Second, the results of the comparative studies are basically correlational and thus say little about the direction of causal influence. For example, believing in High Gods could be either a precondition for the emergence of state-like societies (as the SSP hypothesis seems to suggest) or a consequence of the emergence of such societies. (For example, the hierarchy of the pantheons of gods might have come to reflect the political relations between groups, as occurred in Mesopotamia; see Bottéro 2001.)

The status of the late SSP hypothesis can only be decided on the basis of historical evidence. Unfortunately, we lack such evidence. Perhaps we will never conclusively know whether the late SSP hypothesis identifies an important (or insignificant) factor in the development of large-scale societies. However, I would like to suggest that the almost complete lack of evidence about SSP before the Axial Age supports a negative assessment of the late SSP hypothesis. I am not suggesting that this absence of evidence is evidence of absence. We do know something about early states and the first civilizations (Trigger 2003). If the idea of supernatural surveillance and punishment did play a crucial role in their emergence, one needs an explanation of why it is not present in the 
evidence we have. For example, we know a great deal about the Roman Empire. The Roman pantheon of deities does not contain morally concerned gods, nor do the pantheons of those cultures whose religious ideas the Romans adopted. Of course, Rome ultimately adopted a religion in which the idea of SSP plays a central role, but this occurred much later. We can discuss whether Christianity hastened or delayed the decline of Rome, but it played no role in its rise.

Although we know much less about other and earlier civilizations, I suggest that we can use the absence of SSP in Rome as a template for them. What was possible in Rome must have also been possible elsewhere and earlier. At the least, a belief is SSP cannot be a necessary condition for the evolution of large-scale social cooperation and complex societies. Thus the argumentative strategy in which SSP is presented as the only conceivable mechanism making large scale cooperation possible, is no longer viable, if it ever was. Furthermore, as the non-SSP scenario is thus established as the default option, the burden of proof is on the supporters of the late SSP hypothesis. They should provide evidence of SSP-like beliefs having had a significant influence if their theory is to be a serious contender in discussions about the emergence of the large-scale societies.

\section{The cognitive requirements for theological sophistication}

Why did ancestral hunter-gatherers not believe in SSP? The probable reason is that the idea of an all-powerful and morally concerned god is quite complex and its development has many preconditions. First, the idea does not automatically arise from the everyday attributions of agency, as Bering and his associates seem to suggest. In fact, the formulation of an idea such as this requires abstract thinking and a systematization of beliefs that probably does not occur in small groups having an oral tradition.

As Sanderson \& Roberts (2008) argue, writing and records were crucial prerequisites for the formation of monotheistic religions (which typically include the idea of SSP). Elaborate religious doctrines had to be written down in order to be transmitted successfully across the generations and the systematization of religious beliefs probably required external representation, such as writing. Studies of illiterate contemporary groups seem to support this assumption. Another precondition for theological sophistication is full-time specialized priests who can focus on the systematization of 
religious doctrines. The precondition for this priestly class, in turn, is the development of agriculture and a sufficient surplus of food. Naturally, ancestral hunter-gatherers had not such surplus, and their shamans did not constitute a group that could have developed and sustained detailed religious doctrines. Finally, ancestral hunter-gatherers probably had no motivation to systematize their thinking about spirits, gods, and other supernatural agents, because in contrast with later periods, they did not need to justify a central authority or political relations between different communities. Thus they did not develop such an idea, or if they had, they were unable to transmit it across the generations as it would have lacked both relevance and credibility.

Before concluding this paper, I want to look at some distinctions that the supporters of the SSP hypotheses do not seem to have recognized. The first is between supernatural agency and the agency of an all-powerful god. The second is between the idea of an afterlife and that of a morally contingent afterlife.

Let us begin with the idea of supernatural agency. It is probable that ancestral hunter-gatherers held beliefs about supernatural agents. They did have a full-blown theory of mind and the ability of linguistic metarepresentation, so it can be expected that their "agency detection device" was indeed quite active. However, as I have already pointed out, this does not sufficiently justify the SSP hypothesis. Ethnographic records suggest that believing in active supernatural agents did influence people's behavior, but the abilities of these agents were seen as limited, and the agents were thought to have idiosyncratic preferences. These supernatural agents were simply considered to be factors relevant to everyday life. What is crucial is that they are not particularly morally concerned with human behavior. Rather, they probably had their own, non-moral, agendas that people had to take into account. Thus the gods of the hunter-gatherers were probably more like parental figures or difficult neighbors that people had to learn to get along with, rather than all-powerful agents requiring formal worship. (Rather than being examples for humans, the ancient gods seemed to be exemplars of immoral behavior to whom the rules of human morality did not apply.)

Thus threats or promises of morally motivated divine intervention only become relevant when people develop the theological idea of a morally oriented and motivated deity. And this seems to 
presuppose that they already could conceive of an impartial moral perspective. Precisely when this remarkable idea was developed is anyone's guess, but in any case it indicates that people had to have sophisticated notions concerning morals before they began to attribute idealized versions of the moral perspective to their gods. Similarly, to be able to administer supernatural punishment, the relevant gods had to be relatively more powerful than ordinary spirits and minor deities. The credibility of the threat of punishment decreases significantly if it possible that the penalty might be compromised by the personal agenda's of other deities. Thus a punishing God must be a kind of High God who can override the purposes of the lesser deities.

Note that the idea of divine rewards and punishment for moral behavior is far from self-evident. The ancient hunter-gatherers probably adhered to a view many still hold today: that earthly rewards and punishments are often unfair. Moral transgressors often escape without punishment, and some who abide by the moral codes end up suffering. Without post-mortal punishment, the idea of supernatural surveillance would be a non-starter, at least in the conceptual setting of the SSP hypothesis - recall that the idea was that obedience to norms is a result of self-interested calculation. Thus the idea of a life after death is important for the SSP hypothesis.

Cognitively, ideas about an afterlife are possible after the development of the theory of mind, linguistic metarepresentation, and an ability for "mental time-travel". In the light of archaeological evidence, there is no doubt that our ancestors believed in an afterlife quite early on. However, we know little about the content of their beliefs. It is probable that they varied greatly from culture to culture (as the evidential basis for them is non-existent), but presumably there was also much uncertainty about these matters (again due to non-existent evidential basis) among believers. It is also plausible that beliefs about the "next phase" influenced people's behavior, at least in cases where they believed that they could influence their lot in the afterlife. However, the crucial point from our point of view is that this afterlife originally had no intrinsic connection with morality.

For the idea of an afterlife to have an influence on moral behavior, the afterlife should be contingent on one's moral conduct. Thus while the ancient Mesopotamians did recognize a kind of divine judgment that determined one's faith in the gloomy Netherworld, this judgment was not based on 
considerations of lifetime piety or good conduct (Cooper 1992: 24-26). Such judgment does not provide incentives for moral behavior, although it might motivate individuals to ensure that they would have a proper burial. This point is not limited to ancient Mesopotamia. In many religions the afterlife is dependent on carrying out the proper funeral rites, knowing the right spells, or on the gifts to be given to gods. While these things probably cause people to pay more attention to religious doctrines, they do not make them more moral or prosocial in a strict sense. Similarly, if one's fate in the afterlife is determined by one's social status or the possessions (including slaves) one is buried with, this would motivate people to accumulate wealth and social power, not to behave in a less selfish manner. What is needed is a god (or gods) who decide one's faith based on one's conduct during one's lifetime. These godly figures would have to be both knowledgeable about and interested in people's lives in order not be fooled by the ghosts or spirits of the dead. They should also be impartial, so that they could not be bribed by those attempting to secure a more pleasant afterlife. And finally, they should have the ability to determine where the dead will ultimately end up in the afterlife. None of these ideas were self-evident for ancestral huntergatherers. Rather, the idea of interested, omniscient, impartial and potent god is the product of long development of ideas, and its credibility requires the support of a whole corpus of theological thought.

From the point of view of this paper's argument, what is crucial is that the SSP hypothesis requires that the afterlife be contingent on moral conduct during one's lifetime. This seems to be a relatively recent idea. The first recorded instances are found in the Egyptian Book of Dead that is dated around 1550 BCE. Of course, it is possible that similar ideas had been developed earlier and elsewhere, but it is notable that the idea of morally contingent afterlife was regarded as one of the radical new elements of Christianity when it began to spreading among those peoples that lived under Roman rule. This is not good for the SSP hypothesis.

Supporters of the SSP hypothesis might suggest that we simply lack evidence about the past instances of these beliefs. However, there is an important counter-argument to this notion. It is based on the idea that if people believe that the afterlife is contingent on the manner of death, 
details of burial ceremonies, things one takes with oneself to the grave, or one's ability to bribe or fool the gods, these beliefs provide evidence against SSP. The point is that if people have these beliefs, it shows that they lack any belief in a morally contingent afterlife, or that their confidence in such a thing is rather low. For SSP to be effective in making people behave morally, it must be credible. If the thing is not believed to be real, the effects of the belief cannot be real either.

\section{Conclusion}

If what I have said is mostly correct, we can conclude that the early SSP hypothesis is simply wrong and the late SSP hypothesis lacks evidence. We can therefore conclude that SSP did not play a crucial role in the evolution of human morality and cooperation. The cognitive capacities underlying moral reasoning (altruistic impulses, moral feelings, and reasoning abilities) predate moral religion based on supernatural surveillance and punishment. Thus the fear of God is not the origin of morality. Of course, this leaves us with a set of intriguing questions. How and when did the gods become increasingly moral? How did the scope of morality become universal, and what was the role of religions in this development? Why did the religions having moral gods achieve the dominant position they hold today? (Wright 2009) I have not addressed these questions, but I think we can conclude that evolutionary conjectures such as the early SSP are not part of the answer to them.

However, I also think that a methodological lesson can be learned from this example. Both SSP hypotheses seem rather good exemplars of the dangers of anachronistic story telling. Underlying the anachronistic extrapolations from present day religions to the past, and the misreading of the evidence, lies the assumption that religion is a natural kind whose essence is a belief in SSP. This probably implicit - assumption made by essentialists guides their inferences and clarifies why they find supporting evidence where there is none. Thus their implicit assumption that a moral and powerful god is a prototypical supernatural agent makes it natural for them to presume that the hunter-gatherer beliefs about supernatural agents were beliefs about powerful moral gods. A similar implicit assumption drives their interpretation of beliefs in an afterlife as evidence of a belief in morally contingent one. The same principle guides the interpretation of other pieces of evidence. 
The strong conviction that believing in SSP is at the core of any religion makes it natural to assume that this core feature is responsible for most of religion's effects. Thus the advocates of SSP disregard alternative explanations of their own experimental results and of the studies like Sosis and Alcorta (2003).

The lesson we learn is that we should not treat religion as a natural kind with an essence. What we call "religion" contains a heterogenous collection of very diverse elements - experiences, rituals, doctrines, specific social practices, etc. - that are not organized around some essential core feature. Religion also shows significant historical and cultural variance that can be lost when religion is considered in essentialist terms. Given this, "religion" is not a very good explanatory variable. We should always ask which aspect of religion is the real explanatory variable. This is particularly important when we study human evolution and history before the rise of organized religions. It is not obvious that the factor responsible is always what seems to be at the core of the contemporary western notion of religion - the belief in SSP. It might be that many more mundane aspects of religion are more important.

\section{References}

Apicella, C. L., Marlowe, F. W., Fowler, J. H., \& Christakis, N. A. (2012). Social networks and cooperation in hunter-gatherers. Nature 481 (7382), 497-501.

Atkinson, Q. D., \& Bourrat, P. (2011). Beliefs about God, the afterlife and morality support the role of supernatural policing in human cooperation. Evolution and Human Behavior 32: 41-49.

Barnes, Michael Horace 2000: Stages of Thought. The Co-Evolution of Religious Thought and Science. Oxford University Press.

Bateson, M., Nettle, D., \& Roberts, G. (2006). Cues of being watched enhance cooperation in a real-world setting. Biology Letters 2: 412-414.

Baumard, N. (2010a). Punishment is not a group adaptation. Mind \& Society 10: 1-26.

Baumard, N. (2010b). Has punishment played a role in the evolution of cooperation? A critical review. Mind \& Society 9: 171-192.

Bering, J. M. (2006). The folk psychology of souls. Behavioral and Brain Sciences 29: 453-461.

Bering, J. M., \& Johnson, D. D. P. (2005). “ O Lord You Perceive my Thoughts from Afar”: Recursiveness and the Evolution of Supernatural Agency. Journal of Cognition and Culture 1: $118-142$.

Boehm, Christopher 1999: Hierarchy in the Forest. The Evolution of Egalitarian Behavior. Harvard University Press.

Bottéro, Jean 2001: Religion in Ancient Mesopotamia. The University of Chicago Press. 
Bourrat, P., Atkinson, Q. D., \& Dunbar, R. I. M. (2011). Supernatural punishment and individual social compliance across cultures. Religion, Brain \& Behavior 1: 119-134.

Cooper, Jerrold S. (1992) The Fate of Mankind: Death and Afterlife in Ancient Mesopotamia, in Hiroshi Obayashi (ed.): Death and Afterlife. Perspectives on World Religions. Prager. New York: 19-33.

Dubreuil, Benoît 2010: Human Evolution and the Origins of Hierarchies. Cambridge University Press.

Ekström, M. (2011). Do watching eyes affect charitable giving? Evidence from a field experiment. Experimental Economics 15: 530-546.

Ernest-Jones, M., Nettle, D., \& Bateson, M. (2011). Effects of eye images on everyday cooperative behavior: a field experiment. Evolution and Human Behavior 32: 172-178.

Galen, L. W. (2012). Does religious belief promote prosociality? A critical examination. Psychological Bulletin 138: 876-906.

Hill, K. R., Walker, R. S., Božičević, M., Eder, J., Headland, T., Hewlett, B., Hurtado, A. M., ( 2011). Co-residence patterns in hunter-gatherer societies show unique human social structure. Science 331 (6022), 1286.

Johnson, D. D. P. (2005). God's punishment and public goods. Human Nature 16: 410-446.

Johnson, D. D. P., \& Krüger, O. (2004). The good of wrath: Supernatural punishment. Political Theology 5: 159-176.

Johnson, D., \& Bering, J. (2006). Hand of God, mind of man: Punishment and cognition in the evolution of cooperation. Evolutionary Psychology 4: 219-233.

Johnson, Allen W. \& Timothy Earle 2000: The Evolution of Human Societies. From Foraging Group to Agrarian State. 2nd ed. Stanford University Press.

Kitcher, Philip 2011: The Ethical Project. Harvard University Press.

Marlowe, F. W. (2005). Hunter-gatherers and human evolution. Evolutionary Anthropology 14: 5467.

Norenzayan, A., \& Shariff, A. F. (2008). The origin and evolution of religious prosociality. Science 322: 58-62.

Peoples, H. C., \& Marlowe, F. W. (2012). Subsistence and the Evolution of Religion. Human Nature, forthcoming.

Pyysiäinen, Ilkka 2009: Supernatural Agents. Why We Believe in Souls, Gods, and Buddhas. Oxford University Press.

Roes, F. L., \& Raymond, M. (2003). Belief in moralizing gods. Evolution and Human Behavior 24: $126-135$.

Sanderson, S. K., \& Roberts, W. W. (2008). The Evolutionary Forms of the Religious Life: A CrossCultural, Quantitative Analysis. American Anthropologist 110: 454-466.

Schloss, J. P., \& Murray, M. J. (2011). Evolutionary accounts of belief in supernatural punishment: a critical review. Religion, Brain \& Behavior 1: 46-99.

Shariff, A. F., \& Norenzayan, A. (2007). God Is Watching You: Priming God Concepts Increases Prosocial Behavior in an Anonymous Economic Game. Psychological science 18: 803-809.

Shariff, Azim F., Norenzayan Ara and Henrich, Joseph 2010: The Birth of High Gods: How the Cultural Evolution of Supernatural Policing Influenced the Emergence of Complex, Cooperative Human Societies, Paving the Way for Civilization, in Mark Schaller, Ara Norenzayan, Steven J. Heine, Toshio Yamagishi, Tatsuya Kameda (eds.): Evolution, Culture, and the Human Mind. Psychology Press: 119-136. 
Snarey, J. (1996). The natural environment's impact upon religious ethics: A cross-cultural study. Journal for the Scientific Study of Religion 35: 85-96.

Sosis, R., \& Alcorta, C. (2003). Signaling, solidarity, and the sacred: The evolution of religious behavior. Evolutionary Anthropology: 12: 264-274.

Trigger, Bruce G. 2003: Understanding Early Civilizations. A Comparative Study. Cambridge University Press.

Woodburn, J. (1982). Egalitarian societies. Man 17: 431-451.

Wright, Robert 2009: The Evolution of God. Little, Brown and Company. New York. 